Article

\title{
Gender and Folk-Religion in Western China: A Case Study of the Tu of Qinghai
}

\author{
Haiyan Xing * and Gerald Murray \\ College of Philosophy, Law \& Political Science, Shanghai Normal University, Shanghai 200234, China; \\ murray@ufl.edu \\ * Correspondence: xhydls@shnu.edu.cn
}

Received: 2 August 2019; Accepted: 10 September 2019; Published: 12 September 2019

\begin{abstract}
This paper deals with analysis of gender issues in an ethnic religious system in Western China, the religion of the Tu ethnic group. We focused on gender in Tu religion, which entailed documenting gender dynamics in three major ethnographic domains that have been present in religious systems around the world and through time: spirit beliefs, rituals, and specialists. Though examined gender dynamics as they occur among the Tu in all three of these niches, we found that in the Tu spirit world, there are major male and female spirits who are viewed as having equal status and equal power over the weather. However, in the domain of ritual specialists, the gender situation changes. As for gender-differentiation in rituals, we found practices that excluded women from entering temples and from participating in public emergency rituals associated with weather crises. In addition, we have attempted to identify the multiple causal factors that that may have affected the evolution of Tu.
\end{abstract}

Keywords: gender; folk-religion; religious specialist; Chinese ethnic groups

\section{Introduction}

\subsection{Purpose of the Article}

These pages will deal with analysis of the multiple causal factors that influence the evolution of gender issues in a religious system. We will do this via focused analysis of gender issues in an ethnic religious system in Western China, the religion of the Tu ethnic group. The religion has already been documented in depth by Xing (2015). The multiple forces driving its systemic evolution have been discussed in Xing and Murray (2018).

In these pages, we wish to propose a strategy, first, for a balanced ethnographic documentation of gender issues in religion and, secondly, for analyzing the factors that influence the trajectory of a religious system with respect to gender. With respect to the first, we will first propose a systemic framework for examining gender issues; the basic argument here is that the issues of gender differentiation enter into multiple sectors of any religious system, not just into the gender of specialists. Balanced ethnographic coverage of gender, or of any ethnographic domain, entails examination of that domain as it occurs across the multiple systemic domains that are found in any religious system.

\subsection{Literature Review}

Scholarly writings on gender issues in Chinese religion have a long history. Schafer (1973) examined poetic texts from the T'ang dynasty and makes the case that the spirits controlling the weather in China were originally female dragons, and that in fact the role of shaman was, in ancient China, a female role. After that, Sangren (1983), Ames (1981), Dudbridge (1992), and Adler (2005) discussed the role of women in Daoism and Chinese Buddhism. 
The edited volume by Jia et al. (2014) on Gendering Chinese Religion is a volume containing nine articles dealing with different aspects of gender in Chinese Religion. The introductory essay contains an excellent literature review of recent gender-related studies of Chinese religions. Jia's own article, within the volume, on Daoist priestesses addresses a topic to be discussed in these pages (the gender of specialists), as does Cheung's contribution on menopause ritual. Some scholars, such as Martin (1988), discussed the gender issue in the rite of passage.

In discussing the spirit world of the Tu, we will not only touch on the major spirits who are objects of collective veneration (the dragon kings and the queen mothers). We will also discuss potentially harmful spirits that are feared, particularly the maoguishen, the "cat ghost" or the "cat demon". The historical antecedents to this sinister creature, found elsewhere in China, are discussed by Doran (2015). A similarly sinister theriomorphic spirit—an animal spirit that often takes on human form-is the fox spirit, active principally in Northern China. The historical manifestations of this creature are discussed by Kang (2006). Neither Doran nor Kang carried out systematic field research on these spirits; their treatment is historical. However, they do provide evidence that the cat-demon of the Tu is by no means unique to them. The same can be said of the Tu pantheon in general, which is dominated by spirits who made their way into the Tu pantheon via Daoism.

Our analysis focuses on religious dimensions of gender. Gender issues play a major role in Bryson's $(2013$, 2017) study of the transformation through the centuries of a female Buddhist deity-Baijie-unique to a border region in Southwest China close to Burma, Laos, and Vietnam, and within the cultural region influenced by Tibetan Buddhism. The study was carried out among the Bai 白ethnic group. She provides insights into four distinct phases of Baijie's evolving image: Buddhist deity, royal mother, widow martyr, and contemporary village deity. Her diachronic analysis of transformations of this particular deity within the Buddhist pantheon constitutes a parallel to our own information concerning the evolution through the centuries of several spirit beings in the Tu pantheon.

Also of particular relevance to the study of evolving gender dynamics in post-Mao Chinese religion is the work of Sun (2014), who did eighteen months of fieldwork on women and popular religion in communities in Southeast China. Women played central roles in the reconstruction of temples destroyed during the Cultural Revolution, and most devotees who subsequently attended these temples were women. Older women took on the task of raising money for the temples; their insistence on the matter led otherwise indifferent males to contribute. However, despite female initiatives in these matters, the major ritual and managerial roles, with few exceptions, continued to be assigned by the women themselves to males (some of them Buddhist monks). Furthermore, among the major communal rituals were rain rituals (also found among the Tu) during times of drought. As is also true among the $\mathrm{Tu}$, however, women have to hide themselves from sight and not be seen during the procession so as not to "contaminate" the rituals. We will discuss and analyze the possible causes of this superficially misogynist phenomenon, which is paradoxical, since women themselves in Sun's community were the major organizers of temple restoration.

There is, in short, a growing body of literature on gender dimensions of Chinese religion. On the one hand, our contribution to this body of literature will be information on the religious practices of a particular ethnic group. However, beyond providing one more "ethnographic nugget", we hope to contribute both paradigmatically and analytically. Firstly, we will provide what we consider to be an ethnographically useful tri-partite conceptual schema for analyzing gender dynamics—or other dynamics - within religious systems. Secondly, we will also venture into issues of causal analysis. Changes in religious systems are not whimsical. They are often driven by factors exogenous to the religious system itself. We are interested in exploring how these exogenous factors have influenced the evolution of Tu religion. 


\subsection{Analytic Paradigm: Universal Systemic Niches of Religion}

There are three commonly found-perhaps universally found-components in religious systems that can be used to "operationalize" our use of the term religion.

(1) Pantheon: spirit beliefs. The pantheon is an inventory of the disembodied but conscious and active spirits in whose existence members of a group believe. Spirits are believed to be aware of humans and to influence natural processes and human affairs. They are in turn believed to be amenable to human petitions or sacrifices. There is some "wiggle room" about what to include in the concept of pantheon. The disembodied souls of dead ancestors, though not universally venerated, are believed throughout China to enjoy postmortem survival. We place them in the pantheon. Several impersonal forces found in Chinese culture- the Dao, Qi (energy), Yin and Yang are not considered personalized spirit beings that are aware of an individual and that can be placated. We will not include them in the "spirit pantheon". (Other analysts may wish to include them).

(2) Rituals. Religious systems have a repertoire of system-specific behaviors designed to elicit the attention and control the behavior of these spirits. Rituals can be collective or individual. Rituals are usually repeated, both by the same individual and by different individuals. Not all repeated behaviors are rituals, though they may be so labeled-e.g., daily toothbrushing, shaking hands-in colloquial English. A behavior is a ritual in our terminology if it is part of a process aimed at attracting the attention of spirits.

(3) Specialists: Religious systems also have a leadership structure consisting of individuals believed to be more knowledgeable and/or more powerful to deal with the spirits and guide the rituals. Specialists play quite different roles in different systems. The category includes institutional specialists such as priests, rabbis, and ayatollahs, as well as informal charismatic specialists with no official legitimization who must achieve credibility by successful healing or other services.

These components are found in virtually all religions that anthropologists have documented. Some systems have other elements that are not universals: scriptures, statuary, religiously based sexual codes, and others. There may be other universals besides the three which we have enumerated-sacred times, sacred places, rites of passages, etc. We will focus on the three here enumerated. We will argue that, to discuss gender issues in religion, it is ethnographically productive to examine gender issues in all three structural domains: the gender of spirits, the gender of specialists, and cultural rules that restrict the participation of either males or females in specific rituals.

\subsection{The Issue of Causal Analysis}

Our interest goes beyond synchronic description into the forces driving diachronic change in a religious system. The guiding assumptions in this regard are that (a) religious systems change through time and (b) it is possible to identify at least some of the forces driving such change. The latter entails causal analysis, an intellectual exercise that has had its ups and downs in anthropology. The apogee of interest in causality has long ago passed in the wake of interpretive and postmodern paradigms. However, the search for causes-the posing of the "why" question-is built into the adaptive structure of the human brain and continues to drive much anthropological writing.

In these pages we will circumscribe our explanatory ventures. A distinction must here be made between accounting for the origin of a system and the changes that occur in the system through time. The causal origins of different religious beliefs and practices may be difficult to retrieve. The Abrahamic religions that came from the Near East, for example, focus on a single omnipotent deity, whereas the folk religions of China attribute independent power to multiple deities, without attributing to the lofty Jade Emperor the omnipotence, omniscience, and omnipresence attributed to the Abrahamic supreme deity. (The Jade Emperor relies on annual reports from myriads of local zaoshens, kitchen deities, to make decisions regarding individual families for the coming year.) It is interesting to speculate 
why monotheistic belief- $X$ dominates in one setting and polytheistic belief- $Y$ dominates elsewhere, but a speculation is not a convincing explanation.

There are other causal questions, however, that can be more reliably answered. Our focus is on gender; the gender dimension of Chinese religion has changed through time. Certain preternatural powers that throughout Chinese history have traditionally been allocated to male deities have come, among the $\mathrm{Tu}$, to be shared equally with female deities. Are there identifiable reasons behind this change? On the other hand, we will also document and discuss the exclusion (apparently recent) of females from the role of spirit medium among the Tu. This exclusion has persisted despite the inclusion of women as shamans in other Chinese religious systems and despite the powerful gender egalitarian norms that have transformed the economic and educational roles of women in the PRC as a whole. Why has the opposite occurred in the Tu religious system?

Cultural anthropology is legitimately interested in such causal questions. We will single out such changes in Tu religion and place them analytically in the context of the evolving economic, social, and political forces within which the Tu have been historically embedded. The evolution of political and economic systems has been known to influence the evolution of religious ideologies and practices. The opposite can occur as well; the imposition of an exogenous religious system can transform local political, economic, and familial systems. In the case of the Tu ethnic group, however, the impact of Chinese economic and political systems on Tu religion has been much more powerful than the converse. It will be our intent in these pages not only to describe changes in the gender dimensions of Tu religion but also to identify the ambient forces that have triggered off some of the changes.

The information to be presented in these pages on Tu religion is based on several years of fieldwork by one of the authors, Xing, among the Tu, an ethnic group of which she herself is a member. The other author, Murray, has carried out research on folk-religious beliefs and practices in Haiti. He has also briefly visited Tu communities in the company of Xing. He has provided a comparative perspective from a different world region and has drafted the systemic framework within which Xing's data are here being analyzed.

\subsection{Background on Tu Society and Tu Folk Religion}

The Tu ethnic group (土族) is one of 56 ethnic groups officially recognized during the 1950s by the People's Republic of China. The 2010 Chinese census identified approximately 200,000 Tu living for the most part in the Gansu and Qinghai provinces of China's northwest. Of Mongolian extraction in the distant past, most Tu abandoned, in recent generations, their former pastoral economy and now practice agriculture with livestock as a secondary component of their economy. Though classified under a single label Tuzu (土族), there is substantial linguistic and cultural heterogeneity within the group, so much so that some Tu groups have argued that they should be reclassified. Though concentrated in a fairly subscribed region in China's northwest, different groups of Tu speak mutually unintelligible forms of the Tu language, which current linguistic classificatory principles would classify as different languages. All Tu are fluent in the local Sinitic language, and many have in addition learned the national lingua franca, Mandarin, in school. The Tu language itself is disappearing among the younger generations. However, if both of their parents are $\mathrm{Tu}$, or if one is $\mathrm{Han}$ and the other $\mathrm{Tu}$, they are still classified at birth as Tu, even if the home language is no longer that of the Tu. Because of current educational advantages, if one of the parents belongs to an ethnic minority, they prefer to have their children classified as members of that group rather than as Han. Freedom from the one-child regulation was another advantage when that regulation was still in effect.

In terms of Tu religion, a preliminary analytic caution must be given. Most Tu participate actively in local Tibetan Buddhist temples (officially recognized and financially supported by the Chinese government) in addition to the Tu village temples. To a much lesser degree they also call on Daoist priests for several ritual services. There is no exclusivity in adherence to strictly Tu beliefs of practices. There are nonetheless group-specific ethnic beliefs, practices, and specialists associated with Tu village 
temples. Tu religion can be treated as a system that has been influenced by, but is analytically distinct from, local Buddhism and Daoism.

The Tu religion is practiced only in the Tu homeland in Western China. There is no evidence that Tu migrants to other parts of China bring with them Tu religious practices. Though once officially attacked, as is true of all religions during the Cultural Revolution, and though once endangered, as is still the case with the Tu language, Tu religion has now received de facto governmental support in the post-Maoist years. Though the government does not officially recognize ethnic religions, it does give support to these village-based ethnic temples under the rubric of support to Intangible Cultural Heritage.

A guiding rationale by the State for the support of the Intangible Cultural Heritage of ethnic groups is the goal of income generation for members of the group. In that light, some Tu rituals are now frequently performed in the presence of Chinese tourists who come to the cool northwest plateaus in summer months to escape the heat and pollution of the eastern lowlands. These performances in the presence of interested outsiders have increased the prestige, among the Tu themselves, of otherwise endangered religious traditions. On the downside, there are well-known potential pitfalls of such commodification of folk-religion for tourists. We will argue that the conversion of at least some religious rituals into tourist performances may be one of the factors influencing the evolution of religious gender roles among the Tu.

\section{Gender in the Folk-Pantheon of Western China}

Most of the invisible spirits that inhabit the pantheons of religions around the world are viewed by devotees as active, conscious beings that are aware of humans, can influence humans (positively or negatively), and are themselves open to influence by humans, generally via rituals. The Tu follow the quasi-universal practice of projecting two characteristics onto the spirits of their pantheon: (1) species and (2) gender. Even abstract genderless depictions of God, such as that of the Ein Sof of the Jewish Kabbalah and the eternally pre-existent Logos of Christianity, are derived from scriptures based on anthropomorphic depictions of the supreme deity. The spirits of the Tu pantheon follow the cross-cultural norm in their depiction of spirits as having both species and gender.

\subsection{The Lóngwáng (龙王)—Dragon Kings}

The major spirit in the Tu pantheon is the dragon king, a zoomorphic spirit conceptualized and iconographically depicted as a four-footed wingless dragon. The survival of a major zoomorphic figure is a deviation from the statistical norm in the Chinese pantheon. Most Chinese deities are human in form, most male, some female, who are often believed to have lived in the past as great humans. The zoomorphic dragon king has survived. However, unlike the winged, fire-breathing, destructive monster or Western folklore, enemy to the human species, the dragon of Chinese mythology is a benevolent water-dwelling serpent whose most important service to humans is the provision of rains for the crops.

Chinese Emperors of the past wove images of the powerful but benevolent dragons into their royal garments as symbols of wealth and abundance ${ }^{1}$. Images of preternatural and benevolent dragon power were in fact projected onto the person of Chinese emperors themselves. The Jade Emperor (玉皇 上帝—yùhuáng shàngdì), the mythical supreme deity of the Taoist pantheon, is often depicted clothed in a dragon-embroidered garment. The earthly emperors, prime representatives of the benevolent Dragon, were credited when the rains were abundant; they were blamed (and ashamed) in years of drought. In modern China, the association between political leadership, dragon spirits, and rainfall patterns has been definitively sundered in popular Chinese conceptions. Ubiquitous dragon iconography, however, and the annual folkloric Dragon Boat Festival with races in dragon-shaped boats, preserve the image

1 https://www.ancient.eu/Chinese_Emperor/. 
of the dragon icon as a secular symbol of Chinese culture. The image is now, however, bereft of any widespread popular belief about the Dragon King's real existence or his mystical powers over the rains.

In the ethnic spirit world of the Tu, however, the dragon is alive and well, the source of multiple contributions to the community. These include not only his original rainfall role but also several additional contributions to human life for which he is invoked by the Tu. The original Dragon King of Daoist mythology had already morphed into five distinct Dragon Kings, each with a different color, and each responsible for the rains of different regions in China. Among the Tu, however, the territorial restriction of the dragon has been even more radical. The regional Dragon Kings have disappeared and been replaced by village-specific dragon kings restricted to a particular Tu temple. His power is limited to the surrounding region served by that temple. The word longwang, and the English translation Dragon King, is not the name of a single spirit (as is the unique Jade Emperor). In Tu theology the term longwang refers to a type of spirit being, much like the term "angel" or "devil" in English.

In the religion of the Tu, dragon kings have maintained their status as the principal spirits venerated in many village temples. They have, however, been restricted in terms of their territorial scope. The five regional Dragon Kings of Chinese mythology, each responsible for a particular body of water (including the East China Sea and the South China Sea) are unknown to the Tu. Instead, In Tu folk-theology, each village temple has its own separate dragon king, with no unique proper name, but with a clearly defined territorial sphere of influence limited to the territory served by that temple. (For this reason, our use of the lower-case plural phrase "dragon kings" is warranted.) The village dragon king has been territorially demoted. Each dragon king resides in a spear-length rod housed in his temple. If the rod is stolen and transferred to another village (as has happened), the sequestered spirit's power is now restricted to his new village. Stated differently: in the evolution of popular Tu theology, the dragon king has become a localized tutelary spirit responsible for the well-being, particularly the rainfall, of a specific village or villages served by the temple in which he resides.

\subsubsection{Is the Dragon-King Animal or Human?}

It is also of interest to examine their species membership. Are they zoomorphic-dragon-like in their image? Or are they anthropomorphic deities-human-like deities who have power over the rain-bearing dragons? Chinese iconography has oscillated in this regard. The traditional iconography, whether three-dimensional statuary or two-dimensional portraits or embroidery, depicts serpentine wingless quadruped dragons. In recent centuries, however, images of the "Four Dragon Kings" have begun depicting bearded human kings who presumably have power over the rain-bearing dragons. This anthropomorphic construal of dragon kings, which appears to be more recent, in effect places ultimate control of the rains under bipedal human spirits rather than quadrupedal dragons.

One mythical version indeed has the Dragon Kings subordinate to a negligent Jade Emperor who failed to provide rains. Zoomorphic spirit beliefs, abundant in hunting societies, has yielded in general to an anthropomorphic construal of the spirit world in agrarian societies, in in which domesticated livestock have come under human control. China has been an agrarian society for ten millennia. The traditional Chinese dragon spirit has retained his power over the weather; and he has by no means become a domesticated form of livestock. His depiction, however, has been subject to the same anthropomorphizing tendency that has governed the evolution of spirit iconography in other agrarian societies as well.

In this regard, however, the Tu retain traditional zoomorphic conceptualizations of the dragon kings as dragon in form. Dragon statuary is nonetheless rare. The Tu dragon kings are lodged, not in the statues that are the abode of spirits in Buddhist and Daoist temples, but in what we could call "spirit spears", spear-length sacred rods covered and hidden with cloth decorations. To transfer the dragon king from one place to another, these aniconic spirit-spears are removed and carried on covered litters. There are multiple engravings and drawings of dragon kings found in Tu temples. They are all, however, zoomorphic in form and all are purely decorative in character. The objects of veneration are the spirit-spears, hidden behind cloth covers, not the pictorial depictions of dragons. 


\subsubsection{Is the Dragon Male or Female?}

In terms of gender, we have used the pronoun "he" in reference to the dragon spirit. The title itself, "dragon king" (龙王一lóngwáng), indicates the gender which believers attribute to the spirit in question. The default gender of the Chinese word 王 (wáng) is male, just as with the English word "king". The Chinese word for queen, in contrast, is "woman king"一女王 $n$ ĭ wáng. The Chinese term for "king" refers to a function as the English terms "monarch" and "ruler", but unless the term 女 $(n$ ü ， which means "female") is prefixed, the assumption is a male monarch.

The "dragon monarch" has been conceived of as a male king throughout most of Chinese history. Schafer (1973), however, makes the case that the Dragon King was actually a "Dragon Lady" in earlier $\mathrm{T}^{\prime}$ ang times. In recent centuries there has been a gender change. When depicted anthropomorphically the Dragon King is always depicted as a bearded male, never as a "dragon lady". (The latter term is used now principally as a Western pejorative reference to an Asian female with the inherently aggressive tendencies attributed to the Western fire-breathing dragon, not the benevolent Chinese 龙 lóng). Just as the Chinese polity has been under male control throughout history, so also the Chinese weather has, at least during the past millennium, been likewise under the control of zoomorphic male spirit beings. (We shall see below that this male meteorological monopoly has been somewhat challenged among the Tu.)

The dragon king's major role continues to be associated with the weather, a much more prominent concern among the Tu than among Buddhist and Daoist religious authorities. The Tu long ago abandoned the pastoral nomadic adaptation associated with their Mongolian origin. Farming is their mainstay; livestock raising has been retained as a secondary pursuit. Rainfall at the right time and in the right amount is particularly critical to the agrarian economy. The ritual attention given to rainfall issues has remained central to Tu religion. The village dragon kings have inherited that role from the more powerful regional Dragon Kings of time past. The phases of the ritual year of the Tu follow the phases of the local agricultural cycle. The major collective temple ceremonies-the major focus of collective ritual life that mobilizes community participation and obligatory household donations-all center on rainfall issues. The major role of the Tu religious leaders-both the appointed leaders of the temple committees (all of them males) and the charismatic shamans (also all male) who perform in these collective events as they enter into trance-mediated contact with the spirits -is to ensure the arrival of the annual rains.

In this sense, Tu liturgical cycles differ from those of the Tibetan Buddhism and Daoism that have influenced Tu religion. Buddhism and Daoism also have annual cycles. The ritual cycles, however, do not focus on the agricultural cycles. Buddhist festivals celebrate different events in the life of the Buddha or of other major figures in Buddhist history. Daoist annual festivals also focus on the birth of leaders and deities—of Lao-tzu, of the Jade Emperor, of Guanyin (the goddess of mercy), and others. This non-agrarian liturgical focus has emerged despite the fact that most of the Chinese who have frequented Buddhist and Daoist temples throughout Chinese history have been peasants or agrarian serfs. Neither religion, however, organizes its rich festival sequences to align with the annual phases of the agricultural cycle. The Tu, in sharp contrast, organize their liturgical life in explicit conformity to the phases of the annual agricultural cycle, and the major duty of the dragon king is to provide the rainfall that makes that cycle possible.

The dragon kings are often remiss in that regard. Years of drought may oscillate with equally destructive years of deluges and hailstorms. The Tu community leaders are authorized-nay, obliged - to punish their village dragon king for his negligence or incompetence. They will remove the tutelary spirit from his honored place in the temple and relocate elsewhere the aniconic spirit-spear that houses him, until he performs his meteorological duties, but his major role remains the same: bringing the rains that nurture the agricultural cycle and ensure the well-being of the community.

The village dragon king, however, has also been assigned other functions by the Tu. Though demoted territorially, to the status of village tutelary spirit, his power has been extended into other domains. He has become "multifunctional"; that is, he will be called on to solve other community issues, 
such as conflict, and even issues confronted by individual households. In past decades, the dragon kings were called upon frequently for the diagnosis and healing of illness, though the healing function of Tu religion has dwindled in recent decades.

\subsection{The Niángniáng (娘娘)—Queen Mothers}

Of almost equal importance in the Tu pantheon are spirits who are unambiguously human in form and unambiguously female: the 娘娘 (niángniáng, "noble ladies"), which can be variously translated as queen, empress, imperial concubine, or goddess ${ }^{2}$. We have rendered it as "queen mother" (Xing and Murray 2018) in accordance with what is perhaps her best-known title in Chinese mythology: The Queen Mother of the West (西王母 $x \bar{\imath}$ wáng mŭ, “West Monarch Mother"). Oracle-bone references to her as a supreme heavenly female force precede Daoism. In her pre-Daoist manifestations, she was venerated as a supreme and autonomous female deity. She was later incorporated-some might say "demoted" - as a major female figure into the Daoist pantheon, but now complementary in her functions and subordinate in her status to the male deities that govern the Confucian patriarchal system. The Queen Mother (and similar female figures such as Guanyin) specialize in fertile conception and safe parturition. The female Mother spirit, in short, was not expelled from the pantheon by Daoist theologians. She was simply "put in her proper place", as a companion to, and subordinate to, male deities.

As with the dragon kings, the queen mothers were introduced into the Tu pantheon under Daoist influence. They have also, in a similar manner to the dragon kings, been redefined as territorially localized tutelary spirits responsible only for the region served by the temple that lodges them. The term niangniang refers to a type of female spirit rather than as a proper name.

In this ethnic pantheon they have recuperated some of their autonomous female power of the distant past. They are in no way viewed as subordinate to, or less powerful than, the dragon kings. Nor are they the submissive consorts of any male deity. They are autonomous spirit beings with power equal to that of the dragon kings.

The relationship between the dragon kings and queen mothers is one of autonomous parallelism rather than of functional complementarity. Some Tu temples venerate the female niangniang, others venerate the male longwang. (A minority of temples venerate both.) However, the same powers are attributed to both. In villages where a queen mother, rather than a dragon king, is the tutelary spirit, she is responsible for the rainfall. Stated differently: the powers over the rain which had been allocated in Daoist theology to male Dragon Kings are allocated equally to male and female spirits in the folk-theology and folk-rituals of the Tu.

\subsection{The Zaoshen (灶神)—Kitchen God}

The dragon kings and the queen mothers, discussed above, are physically located in temples. Individual Tu households, however, as is true of households all over China, also venerate the kitchen god. This figure is common all over China and was in fact imported into the Tu religious system from Daoism. The kitchen god is part of a belief complex that roughly parallels Western monotheism in terms of a hierarchically structured pantheon of a high deity with subordinate servant spirits. (The servants in the West are angels. There are traditional Jewish accounts in which each country has its own angel (except for Israel, over which God himself is believed to preside.). Catholicism teaches that each individual is assigned a personal (but unnamed) guardian angel.

The high god in this Chinese case is the Jade Emperor. He resides in his heavenly palace, separate from the world, and depends on his kitchen emissary, the zaoshen (灶神, zào shén), to bring him annual reports on the behavior of each household. The Jade Emperor relies on the zaoshen, who function as

2 https://chinese.yabla.com/chinese-english-pinyin-dictionary.php?define=niangniang. 
an observer (or spy) living invisibly in each household. He will report annually on the behavior of the household members. On the basis of the report the Jade Emperor will allocate rewards or punishment to the household.

Thus, there is only one Jade Emperor for all of China. In standard Chinese mythology, there is also only one zaoshen, Kitchen God, commonly given the proper name zaojun (灶君, zào jūn). For the $\mathrm{Tu}$, however, there are multiple zaoshen, just as there are multiple dragon kings and queen mothers spread among households all over China. No worship is regularly given to the Jade Emperor; he is beyond the reach of ordinary humans and, like human emperors, relies on emissaries to inform him of what is happening. Emperors of the past were permitted to address him. Ordinary people dealt with his emissaries. In this sense he differs from the supreme deity of the Abrahamic traditions, who is omniscient, omnipresent, aware of each human, and accessible to each human. In Tu belief that their domestic zaoshen is their main representative in the court of the Jade Emperor. It is a custom in much of China to make zaotang (a type of sticky candy) in the twelfth lunar month to offer to the zaoshen, in hopes that the candy will make his mouth sweet for a good report or too sticky to send a bad report to the Jade Emperor.

It is thus the household's zaoshen, not the Jade Emperor himself, who is the object of ritual veneration by the Tu. There are two special ritual songs associated with the annual report. One of them is sung to give the zaoshen a sendoff (song zaoshen - "sending off the zaoshen") - before the 23rd day of the final lunar month. The other (ying zaoshen-"welcoming the zaoshen") is sung at the Spring Festival when the zaoshen returns from the heavenly palace.

What is the important issue here is the gender of these deities. Both are unambiguously anthropomorphic - human in form-and unambiguously male. However, paradoxically, among the $\mathrm{Tu}$, it is only married women with children who are allowed to officiate at the domestic altar of the kitchen god.

\subsection{The Dangerous maoguishen (猫鬼神)—Cat Ghosts}

The pantheons of religious systems also contain harmful, dangerous spirits. Most are not usually venerated. However, because there is belief in their existence as invisible spirits, they can be viewed as part of a religious system's pantheon. It is useful to distinguish among three types of dangerous spirits found in different religious systems.

(1) Spirits that are inherently and permanently harmful, such as the demons as represented in Christian traditions. They are not invoked or venerated expect by individuals who enter into a "pact" with them or by countercultural groups that make them the center of a cult, with icons, liturgies, special garments, and specialist leaders, similar to those of conventional religions.

(2) Spirits that are potentially either beneficial or punitive, depending on the ritual attention they receive from devotees. The ancestor spirits of Chinese and Tu tradition are of this type. Many Chinese today may not believe in the survival or the power of the dead ancestors to help or harm them but may do the annual graveside rituals "just in case." The God of the Abrahamic scriptures who rewards and punishes is also of this second type. In the modern Western world, he has been defanged, so to speak, and replaced in many Christian churches by the image of a benevolent grandparent who makes no demands, never punishes, and exists principally to give comforting hugs in times of sorrow. This image is quite different from the reward-and-punishment God-image of the Bible and of the Qur'an.

(3) "Privately-owned" spirits that benefit a human protégé by inflicting harm on the adversaries of the protégé.

The maoguishen (猫鬼神, māo guǐ shén, “cat ghost") of the Tu tradition is just such a spirit. These are harmful and feared zoomorphic cat-like spirits. As is true of the dragon kings and queen mothers, they are (in their normal sate) invisible spirits, but unlike the dragon kings and queen mothers, they are never given iconic representation by the $\mathrm{Tu}$, either as pictures or statues. 
Are they male or female cats? The gender of the maoguishen is itself indeterminate. We will therefore use the pronoun "it", but they are emphatically and unequivocally under the control of a specific human female in the household where they reside. A maoguishen adopts and attaches itself to a particular woman in the household. It is often a daughter-in-law who feels oppressed by her mother-in-law. The husband will know but will feign ignorance and keep silent. The mother-in-law will suspect that her daughter-in-law has a maoguishen, and any oppressive behavior will be held in modest bounds.

Even verbal behavior will be modified in a maoguishen household; knowing that the maoguishen hears everything said in the house, other family members will be careful about what they say to or about the maoguishen's female protégée. The maoguishen in that context functions as a protector of the woman to whom it is attached. Those who do harm to the protégée, even within the household, but particularly outside of the household, will be the target of potentially lethal maoguishen retaliation. If on the other hand family members treat the protégée well, the entire household that hosts it will be beneficiaries of the maoguishen's favor.

Other villagers will also have heard rumors that such-and-such a household is hosting a maoguishen. They will avoid the household. The neighborly inter-household borrowing and lending that is part of local life may not be extended to the maoguishen's home. Fiercely protective of the household's money and belongings, it is known that the maoguishen may harass homes that have borrowed from the host household, even before the return of the borrowed money or item is expected. Young people in the household, particularly girls, may have a hard time finding marriage partners. The maoguishen channels benefits only to its own household. Other households and outside individuals will only be targets of aggression.

A maoguishen household that suddenly begins to experience mysterious misfortunes may believe that the resident cat-spirit is misbehaving. To expel it, the household must call in a shaman to perform an exorcism ritual via the chanting of scriptural texts to expel the now unwanted guest.

The belief in these feline spirits is not unique to the Tu but is instead a common belief in the Qinghai region where the Tu are concentrated (Müller 2009, p. 68) ${ }^{3}$ That is, as is true of the dragon kings and queen mothers, the Tu have incorporated into their pantheon spirits present in the pantheons of the non-Tu populations among whom they live. Alluding to the negative reputation of the maoguishen, Müller refers (in German) to the Qinghai maoguishen as Katzendämonen, i.e., "cat demons". He points out (ibid.) that the maoguishen in Qinghai are "von Frauen verehrt" (venerated by women) and "der Familie der Anbeterinnen Reichtümer bringen" (bring wealth to the families of their devotees). This is precisely the belief found among the Tu.

In addition to the four spirits discussed here-dragon kings, queen mothers, kitchen gods, and cat ghosts-there are other spirit beings in whose existence the Tu believe. Some of them are objects of veneration as well. As is true throughout China, veneration is given annually to the souls of departed ancestors. In addition, because of the influence of Buddhism and Daoism on the Tu religious systems, the icons of additional spirits are placed in Tu temples, but most veneration is given to those discussed here.

\section{Gender and Spiritual Power: Specialist Leaders}

The preceding dealt with the gender of the spirits in the Tu pantheon. Gender dynamics also inform the selection of religious specialists. A pan-cultural distinction is made between religious specialists and ordinary religious participants. Belief in the differential distribution of religious power and authority is an ethnographic universal. Researchers distinguish between institutional specialists and informal charismatic specialists. Among the former are priests, rabbis, ayatollahs, lamas, and others who receive institutional training and whose credibility derivers from their institutional licensing. 
The latter, charismatic specialists such as shamans and spirit mediums, derive credibility from their own demonstration of special powers. However, in all religious systems there are specialists believed to possess greater knowledge of, more intimate contact with, and/or greater power over the spirit world than ordinary human beings.

The question then arises as to whether this specialized authority, knowledge, and spiritual power is equally distributed between males and females, or whether there is gender-based differentiation of specialist roles. The dominant historical pattern across institutionalized religions-Buddhism, Daoism, Judaism, Christianity, Islam, Hinduism - has been to concentrate spiritual authority and power in the hands of males, in tandem with gender differentiation in the concentration of political and economic power. Even institutionalized religious systems that attribute equal spiritual potential to males and females nonetheless traditionally reserve the major public specialist roles to males. Some systems provide institutionally validated niches for female specialists, such as Buddhist and Catholic nuns. Even in these systems, however, major public liturgical roles are reserved for an all-male clergy.

With charismatic specialists, especially those whose principal function is healing, there is a strong female presence. In some settings, such as contemporary urban China, female spirit-mediums and healers appear to outnumber males. The Tu situation, however, emerges as statistically atypical and analytically problematic; the role of shamans is currently assigned exclusively to males. We will examine and attempt to account for this enigma, but first it will be useful to give a brief overview of gender and shamanism in China as a whole.

\subsection{Linguistic Evidence for the Predominance of Female Shamans in Pre-Confucian China}

In the case of Chinese traditional religions, which existed before the formation and spread of Daoism and Buddhism, there are indications of major historical reversals in the gender-based distribution of ritual power. There is evidence, both historical and linguistic, not only that the spirit mediums of ancient China were both male and female, but that the earliest shamanic role may have originally been dominated by women, and that the domination by males of the shamanic role (as occurs today among the Tu) is a product of later developments, including the imposition of Confucian and post-Confucian patriarchal philosophy onto the organization of gender roles in Chinese society as a whole. We will briefly examine evidence in that regard by analyzing the Chinese characters used in earliest times to denote spirit mediums. The characters in question provide hints that spirit mediums in ancient China may have been predominantly or even exclusively female.

Schuessler $(2007,2016)$ has discussed the evolution of the generic word for spirit medium, or seer, or "shaman", which has been from ancient times 巫 $(w \bar{u})$. The character itself has evolved. In earliest times, in the Oracle Bone script of the Shang dynasty (ca. 1788 BC -1122 BC) the character for $w \bar{u}$ was $\Psi$, depicting two pieces of jade placed over each other, believed to be an ancient shamanistic divinatory practice. The character eventually came to refer to both male and female shamans. It is revealing to contrast the $w u$ character with the character for $x i$, which refers exclusively to a male shaman. This word appeared more than a millennium later, in the 4th century BCE. Texts at that time associated the $w u$ exclusively with female shamans, xi with male shamans. As can be seen, the character for the male xi contains the entire character for $w u$, but adds an additional element, the traditional character, which means to "see" or "perceive". The male shaman is depicted in effect as a "wu who sees", or a "seer wu".

Which came first historically: the character for the female $w u$, or the character for the male $x i$ ? The answer is clear. Chinese forms new characters by adding elements to an existing character, not by chopping off elements. The character for the male $x i$ is a later character, derived from and built upon the character for the female $w u$.

We can use modern English occupational terminology to see a similar gender dynamic. The word "pilot" is essentially gender neutral, but because it is culturally associated with males, if the pilot is a woman, she will often be referred to as a "female pilot". The addition of that element suggests strongly the male gender association of the word pilot by itself. When a pilot recently made a heroic landing 
that saved passengers from death, the media lavished praise on her as a "female pilot". When a male pilot had earlier become famous for landing a damaged plane in the Hudson river, he was also praised but never referred to as a "male pilot". The same with the oft heard term "female surgeon". We see the phenomenon in reverse with the phrase "male nurse." When a gender specifier is prefixed to an occupational term, the implication is that those practicing the profession are traditionally members of the opposite sex.

Let us provisionally extrapolate and retroject this pattern to the Chinese characters for female and male shamans. It is clear that the character for male shaman, $\mathrm{xi}$, is not only more recent historically but appends a secondary semantic element to distinguish him from the "unaugmented" wu, presumably female. This is compatible with the proposition that the original and typical shamans were possibly females (just as the original pilots in the West were mostly male). At any rate, the character for the male xi appears centuries after the character for the female $w u$, indicating with high plausibility the chronological priority of female spirit mediums over male spirit mediums in ancient China. This type of "orthographic archeology", digging into the structure of written symbols, does not constitute definitive proof. But it does point the analysis of the evolution of Chinese shamanic roles toward an identification of females as possibly the original practitioners of the profession in ancient China.

In the intervening millennia, the terms $w u$ and xi have survived, but in its semantic evolution the term $w \bar{u}$ has lost its association with one gender and now refers to both male and female spirit mediums. In fact, the term $w \bar{u}$ has now been incorporated into a dimorphemic word that can now refer to "shamanism" or, in English, “wuism". (A more common Chinese word for shamanism is 萨满教, sàmănjiào.)

Among the Tu there are several types of religious specialists, all male.

\subsection{The Temple Custodian and Assistant Custodians}

Each Tu village complex, with its surrounding hamlets, has a Tu temple, similar to but visually and functionally distinguishable from the Buddhist and Daoist temples that also dot the region. Similar to patterns found in Buddhist and Daoist temples, the Tu village temples usually contain different buildings, halls, and shrines.

There is a 21-member elected village committee that manages each temple: qingmiaohui (青苗会， qīng miáo huì, "green seedling association"). Green seedlings refer to crops still growing. The name suggests the original agrarian function of the committee associates with the protection of growing crops. Elsewhere, in northern China, the qingmiaohui patrols circulate around the perimeter of the village to protect growing crops from thieves (Liu 2007; Pan 2017). In the Tu community, the committee has taken on a religious character, but it still functions to enforce agrarian practice. The committee has the authority to collect fines, resolve intra-village conflicts, and enforce community decisions.

However, the green seedling association, at least among the $\mathrm{Tu}$, now functions entirely in the context of the village temple; i.e., it has taken on a religious function. The committee headship is a rotating male position, in principle elected, but in practice assigned through divination practices. The remaining 20 positions, of fewer responsibilities, are also occupied by males.

The custodian's tasks are largely ritual: wiping altars and tables, lighting yak-butter lamps, arranging water bowls, cleaning the temple courtyard. He also burns daily incense and occasional ghost-money offerings. (The latter are make-believe money in different denominations; a person burning them ritually can thus send money to a dead ancestor for use in the abode of the dead, without burning real money. In times of impending weather crises, the custodian has to be present in the temple to take out the sacred spears containing the temple's dragon king or queen mother, to position them for dealing with the weather. In the case of a spirit's failure to provide the expected metereological assistance, the custodian and his associates decide whether to remove the sacred spear containing the spirit to a place of punishment. Stated abstractly, the temple custodian is a ritual specialist. 
He has, however, no special spiritual powers. He manages and organizes but never gets possessed by spirits, never performs ritual dances, never dons ritual garments, and never officiates at healing ceremonies. He nonetheless must be included among the major authorities of Tu village religion.

\subsection{The bo (孛): The Major Tu Shaman}

The $b o$ (孛bó) is the major religious specialist in Tu religion. While the temple custodian does not fit the standard definition of shaman, the $b o$ does. Academics disagree about the precise meaning and boundaries of the term "shaman". The bo would fit into most definitions of the term. He uses special clothing and special ritual paraphernalia (particularly a sacred drum) as he sings special sacred chants and performs sacred dances. He becomes possessed by spirits and plays the role of intermediary between the spirit world and fellow villagers in search of solutions to collective, familial, and individual problems.

The $b o$ of the 21st century has a different emphasis from the bo of times past. As is true of shamans around the world, the $b o$ of the past was heavily involved in the diagnosis and healing of illness. However, the bo currently downplays and has largely withdrawn from spirit healing. That shift away from healing is linked to the spread of institutionalized medicine in China. Chinese now on the whole have access to both Western biomedicine and Traditional Chinese Medicine, those who utilize shamanic healing constitute a dwindling minority.

The most prominent current function of the $b o$ is leadership in the public performance of the collective rituals, largely focused on agriculture and the weather, on which the wellbeing of this agrarian community so heavily depends. In common with shamans in other traditions, the bo uses special religious paraphernalia (principally a drum and special clothing), and performs in public with special chants and special dances.

There is another feature of the bo that is commonly found in shamanistic systems. Unlike the monks and priests at local Buddhist and Daoist temples, the $b o$ is not a full-time specialist deriving all income from ritual services. In daily life he is a farmer or a herdsman, but he has special knowledge and skills that permit him to make the spirits physically enter the community during a special annual three-day festival whose principal goal is ensuring good weather. He is also approached by people in times of personal transition points, illness, or other crises.

The pronoun "he" is used advisedly. Only males may become a bo. Tradition has it that in the past, not only could females function as $b o$, but that the $b o$ were all females. That is now emphatically no longer the case. The $b o^{\prime} s$ clothing may reflect this transition. He has two options in that regard. One costume consists of a long tunic with large red flower patterns and a colorful crown, painted with depictions of spirits that include female spirits. Part of this garb also includes hemp braids for the head. This clothing clearly reflects female dress and is special to the Tu tradition. The other outfit, however, resembles that of Daoist priests: blue robe, black hat, one-sided drum. And the bo, as part of their ritual performance, often read from Daoist texts.

There has, in short, been a syncretic incorporation of Han Daoist practices into the inventory and repertoire of the bo. Though some Daoist traditions elsewhere in China have incorporated women into the priesthood (Kirkland 2004), Confucian patterns of Han patrilineality, patriarchy, and patrilocality have had the heaviest influence among the Tu. The contemporary absence of females among the $b o$ may be the result of a transition that came as an adaptation to Han Daoist influence. Despite the transformation of women's roles that has come since the founding of the PRC, this transformation has not taken place in the Tu religious system. We will discuss this matter in the concluding part of the article.

\subsection{The Shidianzeng(什殿增)}

The shidianzeng (什殿增, shí diàn zēng) is an individual who has a special ability to communicate messages from the spirits by shaking the sacred spear in which the spirit resides. Divination proceeds in public, outside of the temple, as the shidianzeng holds the spear covered in the colorful cloths 
that decorate and hide the spear. Divination usually proceeds on the basis of yes/no questions. Someone poses a question to the spirit. A certain shaking of the spear held by the shidianzeng indicates an affirmative answer. The spirit may also direct the shidianzeng to walk to a certain spot.

As in the case of the bo, the shidianzeng role is reserved to males, usually young males. The shidianzeng's status, however, is different from that of the $b o$. The bo's status is often passed down in families. The shidianzeng is an ordinary individual who demonstrates an ability to be possessed by a spirit and to transmit messages by shaking. The bo has specialized training in terms of chanting, dancing, and reading sacred text; the shidianzeng has none. The bo wears special clothing during his ritual services. The shidianzeng performs his services dressed in ordinary clothing.

Though of lesser status than the bo, the shidianzeng's presence is central to the performance of many rituals. Each temple usually has at least one shidianzeng, a member of the community, so as not to have to call in a shidianzeng from a different temple. There are procedures by which the community selects its shidianzeng, usually from among young males.

\subsection{The Benbenzi (苯苯子)}

The benbenzi (苯苯子běn běn ž̃) is a male villager who has spent time in a Tibetan Buddhist temple or monastery learning to chant certain Buddhist scripts. He is not a full-time or full-fledged monk, but he has learned enough to add a higher-status institutional element to several village rituals. When he performs in these rituals, he will don a garment similar to the clothing of a Buddhist monk. He in fact acts as a lower-cost village surrogate to the Tibetan village monks that villagers often invite to major rites of passage, particularly weddings and funerals.

The benbezi, however, differs from both the $b o$ and the shidianzeng in that he never gets possessed by the spirits as part of his ritual role and would be excluded by most ethnographers from the controversial category of "shaman". He is an ordinary villager whose specialized training and familiarity with Buddhist texts permits him to read such texts in those Tu rituals that would be enhanced by the presence of socially higher elements connected with Buddhist rituals.

We have briefly discussed three Tu specialists that were documented during Xing's (2015) fieldwork. We note again that they are all males. We will see below that there are ritual settings, such as weddings and funerals, in which females are the protagonists and males the observers. In the important annual rituals to a home's kitchen god, it is also the woman of the household who presides at the ritual. However, in neither of these settings is the woman a ritual specialist with spiritual powers that set her apart from the rest of the community. The role of religious specialist, as observed among the Tu, is reserved strictly to males.

\section{Gender and Ritual Restrictions}

We have discussed spirit beliefs as the cognitive element and ritual specialist as the organizational element of religious systems. A third universal element concerns religious behaviors: conventional activities aimed at permitting participants to reach out to spirits, to communicate with them, to gain their favor (or curb their hostility), and to otherwise interact with them. This component is the domain of ritual. In our usage, as stated earlier, the term ritual is reserved for behaviors aimed at gaining the attention of the spirit world. (Repeated conventional secular behaviors, such as toothbrushing and hand shaking, are often referred to in English as "rituals". Such activities fall outside our use of the term. We would classify an Independence Day parade as a secular pageant, not as a ritual. A similarly structured procession of people venerating and following a sacred statue would fall into the category of ritual.)

The discussion of gender-specific specialist roles in rituals has been discussed above. Here we are interested in exploring gender-differentiated patterns of ritual participation by ordinary adherents. Here again we find among the Tu gender-based exclusionary ritual rules that are not reported in most other studies of popular Chinese religion. 
To place these ritual restrictions in context, it is first useful to discuss the general economic and domestic role of women among the Tu. The Tu have long been an agrarian population dependent on heavy male labor principally during the ground preparation phase of the agricultural cycle. Though Tu women do participate in certain agricultural activities, their role is largely restricted to domestic tasks. Especially in the past, they did not engage in the sophisticated embroidery that has permitted women in other ethnic groups, such as the Miao researched by Ye (2013) to reach out to the tourist trade. Nor do they engage in the income-generating marketing activities that one of the authors (Murray and Alvarez 1997) described for Haitian village women. There are growing patterns of temporary labor migration during the agricultural off-season, but the participants in this income-generating alternative are also exclusively male. The income in Tu households is, in short, male-generated and male-managed.

The kinship system itself centers on male offspring. Krader (1955, p. 87) long ago pointed out the exclusive patrilineal character of Tu descent rules. These rules once generated closed corporate patrilineal clans, a pattern that was common throughout traditional China. (The clan system has weakened and lost most of its functions in the People's Republic of China.) This patrilineal kinship system continues to be combined with levirate rules that restrict a woman's options on the death of her husband. A widow is traditionally obliged to marry a brother of her deceased husband, if the latter so chooses. If a woman were to object, the local government would not enforce this levirate rule, but it would require unusual determination and independence to violate local traditions by appealing to local authorities; a woman who successfully resisted might be the object of social ostracism in her community.

\subsection{Women and Ritual Participation}

Before describing some major ritual restrictions to which Tu women are subjected, we should first point out that there are occasions on which the Tu women are the star performers in certain public rituals and the men are relegated to the status of onlookers. This occurs mostly in the universally present subset of rituals called "rites of passage". Weddings among the Tu are a mixture of ritual sadness at the departure of the bride and subsequent ritual joy enlivened by the singing of folk songs. It is the women who lead the ritual mourning at the impending separation, singing songs such as "Crying About Getting Married" and "Complaining to the Matchmaker". It is also the women who will later do the joyful singing at the wedding.

Funerals, another major rite of passage, are accompanied among the Tu by sad music and mournful keening. In principle, the wailing is caused by the inner sorrow of the women wailing. In systemic terms, however, such wailing is an expected element in the event, part of the expected cultural "menu". It is often the collective wailing which engenders the collective sorrow rather than vice versa. It is the Tu women who enact the required performance. Female ritual wailing is common in other cultures as well. There are even cultures where paid professional female wailers are called in for funerals. No such professionals are called at Tu funerals. Ordinary Tu women themselves are expected to perform the ritual wailing.

However, the economic subordination of women to males and the patrilineal and patriarchal orientation of the kinship system have their parallel in several restrictions placed on Tu women with regard to public rituals. They are subjected to taboos which are not common even elsewhere in rural China. We have seen that they are currently excluded from public shamanic roles as spirit mediums. They are also ritually excluded even as participants in certain ritual settings.

- Women are forbidden to enter certain temples.

- Women must hide themselves from sight when certain processions pass by their homes.

- The ritual participation of a woman declines after her marriage. It is reinstated later in life.

- Woman of childbearing age are excluded from many rituals.

- Strong beliefs exist concerning the impurity of menstrual blood.

- Women are considered dangerous after they give birth to a child. 


\subsection{Female Heroines of the Past: Symptom of Diachronic Change?}

The current restrictions stand in paradoxical contrast to legendary and folkloric accounts of the power of Tu women in the past. The Tu women themselves are the repositories and transmitters of stories of the legendary past. The legends and fairy tales of many groups in rural China feature male heroes. In the folklore of the Tu however, the strong, ingenious heroine plays a major role. The women of the past are praised not only for their skills in embroidery, a female activity found in other parts of China as well. They are also depicted as wise and fearless in situations where other traditions recount the deeds of male heroes. Women defeat demonic spirits that are tormenting innocent villagers through assistance which they receive from one or another invisible supernatural power. In such stories the women are often depicted as more powerful and more resourceful than men. For example, in the story "Nayinde A Gu," a chieftain kidnaps and imprisons the heroine, Sister A-Li, and kills her brother. All the males in the village remain in helpless passivity in the face of this murder, but with the help of the magic power of a three-legged horse, Sister A-Li is able to escape.

Older post-menopausal women receive a particularly favorably depiction in Tu oral tradition as beneficiaries of special help from the spirits. For instance, in "Frog Son-in-Law" (青蛙女婿—qing $w \bar{a}$ $n \breve{u} x \grave{u}$ ), an old woman prayed day and night to conceive and bear a child. A child finally emerged from one of her fingers. In "Black Horse" (黑马张三哥—hei mă zhāng sān gē), the sons and daughters of an old woman are eaten by a devil. The woman's black horse gives birth to a boy who then kills the devil for her and rescues her children.

There are other folktales of this genre where beleaguered heroines overcome their difficulties by mobilizing special assistance from the spirits. The special ability particularly of older women beyond childbearing age to be able to marshal help from the spirit world, in situations where men are helpless, is a recurring theme in Tu folklore. It stands in sharp contradiction to the current marginal religious role of $\mathrm{Tu}$ women, many of them focusing on the theme, common not only throughout China, but also Southeast Asia, of the presumably contaminating character of menstrual bleeding. In cultures where this taboo is present, women are typically prevented from entering sacred spaces or participating in sacred rituals during their menstrual cycle. Among the Tu, however, the prohibitions apply permanently to pre-menopausal women, not only when they are experiencing menstruation. Young girls who have not reached menarche go freely into temples and participate in rituals. And it is significant that the above-mentioned folktales concerning the special capacities of Tu women to marshal the benevolent forces of the spirit world focus on older women that have passed menopause.

\section{Possible Causal Factors}

The preceding pages have gender issues in Tu religion in the context of a systemic paradigm that distinguishes among three universal components of religious systems: spirit beliefs, specialists, and rituals. These refer in general to the cognitive, organizational, and behavioral dimensions of religious systems. We have discussed the manner in which gender issues appear in all three domains.

In these final pages we will go beyond description and deal with the more complicated issue of explanation. The most common strategy that has been used in anthropology to "explain" religious belief and practices is "functional analysis." The analyst detects utilitarian functions served by the belief or practices and "explains" the belief or practice on the basis of these useful functions. The functions can be useful to the religion's individual adherents (e.g., comfort in distress) or to the group as a whole (creation of social solidarity.) The function can be useful to an outside actor but harmful to the group and its individuals. Marxist "opiate of the masses" analysis falls into that category. Multiple other functions-e.g., ecological functions, health-protection functions, agrarian functions, cognitive functions, and others-have been discovered (or in some cases probably invented) by analysts interested in explaining religion.

Some proponents of functional analysis make the claim that the functions which they have detected explain the origin of the religious belief or practice. The leap from functions to origins is a questionable leap. A demonstrable function of the spread of the automobile has been the facilitation of extradomestic 
sexual encounters. Was the automobile therefore invented for that function? The obvious silliness of an analysis can be less obvious when dealing with esoteric religious beliefs and practices. Ongoing functions do not explain origins.

We will avoid questions of the remote origins of gender-differentiated religious beliefs and practices among the Tu. Our explanatory efforts will focus more on the exogenous forces that have triggered off changes in these patters, or that enigmatically fail to produce change when it could have been expected. To remain consistent, we will organize the brief discussion in terms the three subsystems that have guided our presentation: the spirit pantheon, the specialist roles, and the ritual practices.

\subsection{How Have Tu Female Deities Achieved Relatively Equal Power with Male Deities?}

The question refers to the fact that the niangniang queen mothers are called upon by the Tu for assistance with the weather, a domain that in China has traditionally been associated with dragon kings. The involvement of the queen mothers with weather seems to be the product of a general metamorphosis of the pantheon in Tu village religion. In traditional Chinese mythology, female spirits tend to associated with fertility and male dragon kings are associated with the weather. Likewise, in Daoist temples different spirits, each housed over a different altar, have functional specializations. One specializes in healing, another in wealth, another in helping young people pass the college entrance exam, another in finding a spouse, and so on.

In the theology of Tu villagers, in contrast, we have pointed out that spirits are "demoted" territorially. Each dragon king or queen mother has power over, and is venerated by, only members of the community served by the temple. There is a clear territorial delimitation of boundaries. But by the same process of theological metamorphosis their functional powers are expanded. The association of a spirit with a specific problem set is replaced by a generalized functional assignment to the solution of the gamut of problems felt by the villagers. Most temples have either a dragon king or a queen mother. The queen mothers in the latter temples are assigned the same roles as the dragon kings in other villages. They are thus called upon in the weather rituals which constitute the major events in the Tu liturgical cycle.

The allocation of equal power to the female deities by the Tu cannot therefore automatically be interpreted as a female protest movement against a patriarchal pantheon. Instead, it seems to be a secondary side effect of broader theological transformations in which Daoist and Buddhist deities have become territorially localized, on the one hand, and functionally diversified on the other.

The absence of Tu female shamans seems to be anomalous in the context of Chinese folk religions. Female spirit mediums have been documented all over China. A major question-somewhat of an enigma-is the exclusion of Tu women from the role of shaman. We have discussed evidence, including the shaman's clothing, that women may have been shamans in the past. There are two separate questions.

\subsection{Why Are There No Longer Female Spirit Mediums among the Tu?}

There are two major systemic processes that may have contributed to the current male monopoly of religious leadership roles: (1) the spread of biomedicine and TCM that has led to a dwindling of shamanic healing, and (2) the impact of State policy with respect to the linkage of Intangible Cultural Heritage with increased internal tourism in China.

Whereas healing is part of the repertoire of male shamans, women and children (the major patients) have traditionally gravitated toward female healers. Biomedicine and Traditional Chinese Medicine have spread to all areas of China, including during the apogee of "barefoot doctors". (TCM is based on natural forces, and is antagonistic to spirit healing or shamanism.) With the discontinuation of the barefoot doctors' program, improvements in infrastructure and the transportation system have still placed most Chinese within reach of modern medical care. The credibility of shamans and their spirit healing technique has plummeted in the population at large. In sectors where a need is still felt, 
most of the practitioners are women healers. The Tu who require shamanic healing services now seek out local female healers among the local majority Han population.

Government policy has intensified the process of male shamanic monopoly among the Tu. There has been continuing hostility on the part of the authorities toward spirit healing. In a historical about-face after the Cultural Revolution, the Chinese government has for decades been promoting and financing religious systems, officially in the case of Buddhism, Daoism, Islam, and Christianity, informally in the case of village religions. The latter are supported under the rubric of the Protection of Intangible Cultural Heritage, and ethnic groups are encouraged to perform traditional songs and dances, wearing their colorful ethnic garb, in the presence of Chinese tourists from other regions. However, shamanic healing rituals are generally (and often emphatically) excluded from the repertoire of cultural practices that local officials are interested in preserving and displaying to outside visitors. They are considered superstitious. Tourists may be entertained by songs and dances performed in colorful garb. They would laugh mockingly at the performance of healing rituals using what would be dismissed as unintelligible gibberish and which at any rate are usually performed in private.

This means that the bo, the major Tu shaman, who wishes to be included among local experts officially designated (and funded) as recognized "culture bearers" would be wise to downplay or cloak his involvement in spirit healing. For a cluster of reasons such as these, the participation in healing rituals of the male $b o$ and other male spirit mediums among the $b o$ has been on the wane. (Spirit healing is still practiced, but mostly by local Han spirit-mediums, mostly women, to whom the Tu will go.) The major contemporary role of the $b o$ is in the performance of weather rituals. It may well be that the major role of female shamans in the past was centered on healing rituals. Those are not part of the repertoire of traditional practices financed by the Chinese State for income-generating presentations to tourists. Females are thus absent from public ritual leadership roles in the current Tu religious system.

And a final observation can be made on this issue. Even in those variants of Daoism and Buddhism which have female specialists, public performances and public religious leadership roles are still done by males. Thus, the domination of public rituals by male specialists is actually in line with what occurs in the two religious systems that, locally, have had the heaviest impact on Tu religion. With the downgrading of the spirit healing function, which was the major function of female spirit mediums, females have been edged out of the shamanic arena. As pointed out, Tu in search of spirit healing services will go to local Han women who specialize in the art. Why these have not survived among the Tu remains an enigma. However, the domination by males of public shamanic performances among the Tu is simply a reflection of the male leadership that exists also in the Daoist and Buddhist traditions that have exerted such an impact on the Tu religious system.

\subsection{Why Have New Egalitarian Gender Roles in China Not Penetrated the Tu Religious System?}

The emergent gender-egalitarian norms now governing much of social life in the PRC have not made themselves felt in Tu religion. The answer is again to be found in the behavior of systems. Politically mandated gender-egalitarian roles in certain areas of economic and social life have not had a demonstrable impact on gender roles in any religion practiced in China. Governmental policy toward religion during the Cultural Revolution and the final decade of Mao's life was not to reform religion, but to eradicate and destroy it. Religious belief and practice were driven underground.

When religious systems re-emerged after the proclamation of religious freedom in the early 1980's, they emerged in their earlier form, insofar as traditional beliefs and rituals could be reconstructed in a landscape of destroyed temples and scriptures consigned to bonfires. And as the Chinese State began its financial support of five official religions, it had no interest in the theological or ritual systems per se, or in coaxing temples, mosques, or churches into gender egalitarian pathways. Its generic concern was to convert religion into a vehicle of the new value placed on "social harmony" and above all to head off any attempts to use religion as a vehicle of social protest.

The government, in contrast, had a hands-off policy with respect to spirit beliefs and rituals. There was no attempt to force temples, mosques, or churches to promote rituals venerating Mao Zedong 
or to oblige congregations to sing hymns to the glory of the Party. However, since the opening of the 1970s and 1980s, religions functioned in the shadow of the State but have been left to their own theology and rituals. (There are indications that this hands-off governmental stance may now be changing.) However, as Tu religion re-emerged after the opening, it did so in the patriarchal mode which had crystallized, under the influence of local Daoism and Buddhism, long before the Cultural Revolution.

\subsection{Rituals: Why Are Women Excluded from Temples and Rituals}

The exclusion of women from entering certain temples and from participating in certain public rituals appears idiosyncratic in the context of other reports on women in rural China. Women enter freely into Daoist and Buddhist temples. Internal tourism in China often entails travel to religious sites. Female tourists are not excluded from such sites. The exclusionary Tu pattern seems anomalous.

The enigma is partially resolved by noting that the exclusion applies not to women in general but to women of childbearing age. There is no restriction for pre-menarche girls or post-menopause older women. There is nothing inherent in female status that is considered inappropriate for ritual participation. The exclusion of the child-bearing cohort from ritual participation is explicitly linked to the fact that they still menstruate. In other words, the exclusion is best linked causally to the presence of persistent menstrual taboos, beliefs about the contaminating impact of menstrual blood. (The same contaminating impact is attributed to the blood shed by a woman at the birth of a child.) What is operating here, therefore, is not a principle that excludes women qua women, but that excludes women of the age group that may be polluted by menstrual blood. We will not venture here into questions of the anthropological origin of menstrual taboos, but whatever their origin, once present in a particular culture, they exert a causal impact on other dimensions of life. Among the Tu, these beliefs appear to be largely responsible for the ritual restrictions placed on Tu women. This belief in the contaminating impact of menstrual blood is found in different cultures in other world regions, not just in China, and not just among the Tu. It is particularly prominent in Asia. The exclusion of adult women from temples and from certain public rituals is causally linked to this belief.

Several questions remain unanswered. Religious systems that define menstrual blood as polluting usually impose restrictions on adult women only during their monthly periods. This pattern is seen even in the modern world, and not just among the uneducated. Orthodox Jewish women with M.D.s or Ph.D.'s in modern hospitals or on university faculties willingly follow religious restrictions during their monthly niddah period. One distinguishing feature of the Tu restrictions, however, is that they apply to women for the entire period that they are in that childbearing cohort, not merely when they are having their menses. That may be atypical cross-culturally and even within China.

A larger causal question was posed above (though not answered with any certitude). Why do some religious and cultural systems focus on the contaminating impact of menstrual blood, whereas for others it is not an issue? That cannot be answered here. We take for the moment the existence of Chinese menstrual taboos as a given and trace the impact of these taboos as they are maintained among the Tu. The remote causes of the taboos may be unknown, but their consequences among the Tu take the form of the ritual exclusion that we have described. Do similar menstrual taboos in other parts of China restrict exclusionary measures only to the menstrual period itself? Or do they apply them, as do the Tu, to all women who are in the post-menarche pre-menopause cohort? That is a matter for future research.

\section{Summary and Conclusions}

Our approach to the study of gender in Tu religion entailed documenting gender dynamics in three major ethnographic domains that have been present in religious systems around the world and through time: spirit beliefs, rituals, and specialists. All religious systems have at least these three systemic "niches"; each culture fills them in differently. Such a systemic overview of religious systems gives ethnographers methodological clues as to where to begin documenting a specific phenomenon such as gender differentiation as it affects religious systems. By way of cautious disclaimer, the use of 
these three focal points in no ways exhausts the discussion of the complex issue of gender as it relates to any particular religious system, including that of the Tu. We simply propose these three systemic "niches" as a useful ethnographic starting point for guiding a researcher in coverage of the manner in which gender dynamics enter into the functioning of any religious system.

To summarize the Tu spirit world: in the active Tu pantheon, there are major male and female spirits who are viewed as having equal status and equal power over the weather. The power of the spirits is localized and confined to the specific community served by the temple in which the spirits are lodged. However, there is no difference between the male dragon kings and the female queen mothers in terms of the problem sets in which they can intervene, nor is there any difference to the powers attributed to them. Even the niangniang, the queen-mother spirits, among the Tu have power over the weather, a role traditionally attributed in China to the male Dragon Kings. The kitchen gods among the Tu are specific to each Tu household. The domestic kitchen gods are male, but the rituals addressed to them are headed by females in each household. The supreme deity in the Daoist pantheon is the Jade Emperor, but no rituals are addressed directly to him by the Tu. He is a remote figure not part of the active pantheon toward which the Tu direct their rituals.

In the domain of ritual specialists, the gender situation changes. We have discussed four major ritual leadership roles. All of them are assigned exclusively to males, but we have pointed out that the Tu rituals over which male specialists preside are all in the public domain. The same patriarchal leadership patterns occur even in the public rituals of Daoism and Tibetan Buddhism. Female ritual power throughout China expresses itself principally in private healing rituals rather than public calendrical ceremonies. These collective calendrical rituals have become strengthened by support from the Chinese State for "Intangible Cultural Heritage" that can generate income by being displayed to tourists. Spirit healing rituals, in contrast, are viewed by the Chinese State (and much of the Chinese public) as obsolete superstitions. The major female rituals among the Tu, spirit healing rituals, have been demonized and made an object of official ridicule. The male dominance of public rituals among the Tu is thus not anomalous in the context of Chinese rituals in general. What is anomalous is the disappearance of female healers among the $\mathrm{Tu}$, for which there is evidence from the past, and the current dependence of Tu women and children on Han female healers.

As for gender-differentiation in rituals, we found practices that excluded women from entering temples and from participating in public emergency rituals associated with weather crises. We have pointed out, however, that these exclusions apply principally to post-menarche and pre-menopause women and are associated with beliefs common through China and Southeast Asia concerning the impurity associated with menstrual blood. Among the Tu these exclusions apply to all females in the childbearing cohort, not merely to those currently menstruating.

We have gone beyond descriptive documentation and have attempted to identify some causal factors, exogenous to the Tu religious system itself, that may have affected the evolution of gender dynamics in the Tu religious world. We have seen that these exogenous forces are located not only in the economic and socio-political forces that have transformed life in the People's Republic of China. They also emanate from the socially powerful institutional religions Daoism and Buddhism. On the one hand, Tu religion cannot be analytically classified as simply a subset of either Daoism or Buddhism. On the other hand, however, we have avoided reifying it as an autonomous "stand alone" ethnic system immune from influences emanating from China's formally recognized institutionalized religions. Influences from Islam and Christianity are minimal-to-absent. Influences from Daoism and Buddhism have, in contrast, been major. Our use of a systemic paradigm is one conceptual tool that permits analysis of causal interactions among different religions. In addition to the economic and socio-political forces that have transformed life in the People's Republic of China, these two major Chinese religious traditions have also exerted an impact on the evolution of gender dynamics in the pantheon, the ritual complex, and the specialist roles of the Tu ethnic group.

Author Contributions: H.X.: Funding acquisition, Investigation, Data curation, Resources, Writing-original draft Preparation. G.M.: Conceptualization, Methodology, Writing—original draft, Preparation, review \& editing. 
Funding: The Project Supported by National Social Science Foundation of China (Grant No. 17BMZ047).

Conflicts of Interest: The authors declare no conflict of interest.

\section{References}

Adler, Joseph A. 2005. Women in Daoism, Buddhism, and Confucianism. Paper presented at the ASIAN Network Annual Meeting, Whittier, CA, USA, April 23.

Ames, Roger T. 1981. Taoism and the androgynous ideal. In Women in China: Current Directions in Historical Scholarship. Edited by Richard W. Guisso and Stanley Johannesen. Youngstown: Philo Press.

Bryson, Meghan. 2013. Baijie and the Bai: Gender and Ethnic Religion in Dali, Yunnan. Asian Ethnology 72: 3-31. Bryson, Meghan. 2017. Goddess on the Frontier: Religion, Ethnicity, and Gender in Southwest China. Stanford: Stanford University Press.

Doran, Rebecca. 2015. The Cat Demon, Gender, and Religious Practice: Towards Reconstructing a Medieval Chinese Cultural Pattern. Journal of the American Oriental Society 135: 689-707. [CrossRef]

Dudbridge, Glen. 1992. Women pilgrims to Taishan: Some pages from a seventeenth-century novel. In Pilgrims and Sacred Sites in China. Edited by Susan Naquin and Chün-fang Yü. Berkeley: University of California Press, pp. 39-63.

Jia, Jinhua, Xiaofei Kang, and Ping Yao, eds. 2014. Gendering Chinese Religion: Subject, Identity, and Body. New York: SUNY Press, ISBN 978-1-4384-5308-8.

Kang, Xiaofei. 2006. The Cult of the Fox: Power, Gender, and Popular Religion in Late Imperial and Modern China. New York: Columbia University Press.

Kirkland, Russell. 2004. Taoism: The Enduring Tradition. London and New York: Routledge.

Krader, Lawrence. 1955. Principles and Structures in the Organization of the Asiatic Steppe Pastoralists. Southwestern Journal of Anthropology 11: 67-92. [CrossRef]

Liu, Chang. 2007. Peasants and Revolution in Rural China. London: Routledge, ISBN 9781134102310.

Martin, Emily. 1988. Gender and Ideological Differences in Representations of Life and Death. Berkeley: University of California Press.

Müller, Shing. 2009. Über die mao-Katzen im alten China. In Tiere im Alten China: Studien zur Kulturgeschichte. Wiesbaden: Harrassowitz Verlag, pp. 49-76.

Murray, Gerald, and Maria Alvarez. 1997. A Haitian peasant tree chronicle: Adaptive evolution and institutional intrusion. In Reasons for Hope. Edited by Anirudh Krishna, Norman Uphoff and Milton J. Esman. West Hartford: Kumarian Press.

Pan, Yi. 2017. Rural Welfare in China. Cham: Springer.

Sangren, Steven P. 1983. Female gender in Chinese religious symbols: Kuan Yin, Ma Tsu, and the 'Eternal Mother'. Signs 9: 4-25. [CrossRef]

Schafer, Edward H. 1973. The Divine Woman: Dragon Ladies and Rain Maidens in T'ang Literature. Berkeley: University of California Press.

Schuessler, Axel. 2007. An Etymological Dictionary of Old Chinese. Honolulu: University of Hawaii Press.

Schuessler, Axel. 2016. Ancient China and the Yue: Perceptions and Identities on the Southern Frontier, c. 400 BCE-50 CE. Journal of Asian Studies 75: 1110. [CrossRef]

Sun, Yafei. 2014. Popular Religion in Zhejiang: Feminization, Bifurcation, and Buddhification. Modern China 40: 455-87. [CrossRef]

Xing, Haiyan. 2015. Social Maintenance and Cultural Continuity-Folk Religion among the Tu in the Northwest China. Ph.D. dissertation, University of Florida, Gainesville, FL, USA.

Xing, Haiyan, and Gerald Murray. 2018. The evolution of Chinese shamanism: A case study from Northwest China. Religions 9: 397. [CrossRef]

Ye, Yinyin. 2013. Embroidery, Gender and Self-representation of the Miao Women in the Southeast of Guizhou. Journal of Cambridge Studies 8: 19. [CrossRef] 